\title{
Overview of Forest Fire Propagation Research
}

\author{
DOMINGOS VIEGAS \\ ADAI/Department of Mechanical Engineering \\ University of Coimbra \\ Rua Luis Reis dos Santos, 3030-788 Coimbra, Portugal
}

\begin{abstract}
Forest fires are one of the major threats to natural and human built environments and have shown a tendency to increase in recent years. They are the result of several combined natural and social factors making their study and management particularly difficult and requiring the intervention of several scientific fields. One of the major issues of forest fires is associated with the combustion and propagation processes. An overview of physical processes linked to fire propagation, especially under extreme conditions will be presented. Emphasis will be given to fire safety and to the protection of human life during fire spread. Case studies and the results of the research program carried out by the author are presented to illustrate some of the topics dealt with in the presentation.
\end{abstract}

KEYWORDS: wildfires, fire growth, flame spread, modeling.

\section{INTRODUCTION}

Fire is a natural event on Earth and its presence in the forest is required to support or enhance regeneration processes in fire-prone ecosystems. Fire has also been used by humans since ancestral times to better control the growth of plants or to modify the use of land. In these forms fire can be considered as beneficial both from an environmental and from a social point of view. But unfortunately fire can spread out of control and produce undesired effects in what we designate as a wildfire or simply a forest fire, regardless of the type of vegetation that may be supporting its propagation.

Forest fires are perceived as being one of the major natural risks in many parts of the world as they may cause the destruction of extensive areas of land covered by various types of vegetation and can disrupt socioeconomic activities and even destroy human lives. The social perception of forest fires is generally associated with the problems that they can create in inhabited regions like Southern Europe, North America or Southern Australia, but by far the largest extent of burned areas occur in remote areas like Central Africa, Amazonia and some boreal regions.

With the rise of temperature that has been observed during the last few decades and the associated changes in climatic conditions, the problem of forest fires has increased in many regions both in number and intensity. Studies on the predicted effects of climate change, namely the work done by Carvalho [1], indicate that forest fires will become worse in some regions where they have already occurred and will extend to other regions that did not have fires in the past, namely in Central Europe.

The complexity of forest fire management and research requires a multi-disciplinary approach to these issues. Given the large number of processes and factors that occur in a forest fire, covering several orders of magnitude of space and time scales, the involvement of scientists with different specialized backgrounds is required to better understand and manage forest fires. The following list of some of the problems associated to forest fire research can provide an indication of the number and diversity of disciplines that can be considered: land use planning and management, forest planning, management and exploitation, fire ignition (human and natural causes), fire detection, remote sensing, role of climatic and meteorological factors on fire ignition and spread, fire propagation, smoke dispersion, health effects, fire control and suppression, fire effects on the environment and on the socio-economic activities, response of the ecosystem to fire, recovery of burned areas, fire safety, decision support tools, and use of communication and computation technologies.

In spite of the strong relationship that exists between human activity and the occurrence and spread of forest fires in many regions, physical factors such as climatic and meteorological conditions play a very important role in the entire processes. Without neglecting the importance of socio-economical aspects, management and consequences of forest fires in this paper, greater attention is given to physical factors and to fire propagation. In the opinion of the present author, fire spread or propagation is a central issue of the forest fire problem as practically all other fire research and fire management aspects are related to the form in which fire spreads for 
the given internal and external conditions that prevail when a fire occurs. The ability of predicting the behavior of a fire has been a goal for many generations of researchers but it can be said that no general model to predict fire behavior in arbitrary conditions is yet available.

In this paper some general aspects of fire behavior modeling and the approach given by the present author and his team for some particular types of fire spread is described, as well as their relevance to fire safety.

\section{GENERAL ASPECTS OF FIRE BEHAVIOUR MODELING}

\section{Modes of Fire Propagation}

Forest fires can spread with one or more of the following modes:

(i) Smoldering or ground fires - those that spread consuming the organic layer above the mineral soil, usually without flaming. These fires spread with a very low rate of spread and therefore they do not cause safety concerns. Given the fact that they can last for long periods and release large amounts of smoke to the atmosphere and may produce a strong and harmful heath impact on the soil and on the organisms near the ground their relevance cannot be underestimated. Peat lands are prone to sustain this mode of fire spread.

(ii) Surface fires - those that spread consuming the vegetation above the ground surface, like for example forest litter, herbaceous vegetation, shrubs and small trees. These fires usually spread with a flaming fire front that consumes the fine parts of the vegetation, mainly dead material that tends to have lower moisture content. This mode of fire propagation is the most common and it is also the best studied mode.

(iii) Crown fires - those that spread through the green canopies of trees and shrubs usually with the support of the surface fire that spread in at ground level. These fires can spread quite rapidly, release very large amounts of energy and completely destroy vast tracts of forest having a great impact on the environment. In spite of their destructive power, crown fires do not create a very important direct risk for personnel safety given the fact that due to their large intensity firefighting is not even. Indirectly they can endanger the life of people both with their impact on urban structures or indirectly through the production of embers that can then initiate spot fires.

(iv) Spot fires - those that are caused by burning particles that are released by the combustion of many types of fuels, when they land on adequate fuel beds and produce new ignitions. Spot fires can be very dangerous as they can initiate new fires behind a fire suppression team that may be caught by surprise between two fire fronts.

\section{Modeling Aspects}

The main objective of modeling fire propagation is to be able to predict the development of the fire front for a given set of boundary conditions that are defined below, including the position of the ignition source. In order to estimate the perimeter of the fire front at given time periods it is necessary to determine the rate of spread of the fire at a large number of points of the fire perimeter in each time step.

It is generally accepted that fire propagation, namely the rate of spread of a given point of the fire perimeter, depends on the following set of factors:

Fuel properties - forest vegetation can be considered as a porous solid fuel that is composed of particles of different sizes and chemical composition, which can be alive or dead and be distributed in one or more strata on the terrain (ground fuels, surface fuels and crown fuels).

Meteorological conditions - associated with climate and weather conditions that are defined by a large set of parameters, like for example air temperature and humidity, wind velocity and direction, solar radiation, atmospheric stability and precipitation.

Topographical conditions - that are associated with the terrain configuration, altitude, slope, orientation, and affected by the presence of other elements in the area of interest.

It is easy to recognize that these three sets of factors are not independent as for example topography influences the wind field and precipitation and therefore will affect the vegetation cover and its properties. In spite of this interaction it is common to deal with these three sets of parameters separately as each one of them has a specific effect on fire spread. In some simplified analyses of fire spread that will be referred to later, it is even common to retain a reduced number of parameters characterizing each factor, namely: (i) fuel moisture 
content $m_{f}$ (defined as amount of water contained in the fuel and expressed as a percentage of its dry mass) to characterize a given fuel bed; (ii) the wind velocity $U$ (measured at a predefined height above the ground or the fuel bed) to characterize the role of meteorological conditions, and (iii) the slope angle $\alpha$ of the terrain to characterize the topographic properties.

Following the review made by Sullivan [2-4] the following problems associated to fire spread can be identified:

Chemistry of combustion: (i) fuel chemistry; (ii) combustion reactions; (iii) solid phase reactions; and (iv) gas phase reactions.

Physics of combustion: (i) advection or fluid transport; (ii) buoyancy, convection and turbulence; (iii) radiant heat transfer; (iv) solid fuel transport; (v) atmospheric interactions; and (vi) topographic interactions.

The list of processes to be considered in fire spread modeling gives an indication of the range of problems and of space and time scales to be dealt with, which make the task of predicting fire propagation in real conditions extremely complex. To cope with this complexity there is a range of model types that try to address the entire process or some parts of it.

Following the classification of model types proposed, the following approaches to fire propagation modeling can be identified:

- Physical models - those that consider both the chemical and physical processes in the model.

- Quasi-physical - those that consider only the physical processes in the model.

- Quasi-empirical - those that consider physical processes and use empirical data obtained either in the laboratory or field tests.

- Empirical - those that consider only empirical data in the model.

Some models are implemented in fire behavior prediction tools or simulators that require input data on the boundary and initial conditions, and provide as an output the perimeter of the fire and other fire properties at given time steps. Physical and quasi-physical models like the ones developed by Linn [5], Morvan and Larini [6], and Sero-Guillaume and Margerit [7] associated with the developments in numerical methods and in computational power will be used in the future to predict fire behavior. However, this is not yet the case, as the required data and informatics requirements presently do not allow to run these models faster than real time for full size conditions. For this reason the models that are currently used in operational simulations are either empirical or quasi-empirical.

The approach that is described in this paper can also be considered as quasi-empirical as some physical laws are used in the modeling but the solution to the problems is made using experimental data obtained both in the laboratory or field tests and also in real fires. Given their relevance to fire safety some aspects of surface and spot fires will be addressed in this overview.

\section{DYNAMIC FIRE BEHAVIOUR}

\section{Basic Rate of Spread}

The simplest case of fire spread that is considered in many mathematical models is that of a linear fire front spreading on a homogeneous fuel bed on a horizontal surface in the absence of wind [8]. In principle this rate of spread that we designate as basic rate of spread $R_{o}(\mathrm{~m} / \mathrm{s})$ depends only on the fuel bed properties. Its value can be measured in laboratory or field experiments but it can also be estimated using fire behaviour models like for example the one developed by Rothermel [9].

In the present paper we shall use the basic rate of spread as a reference to define the non-dimensional rate of spread $R^{\prime}$ that is given by:

$\mathrm{R}^{\prime}=\frac{\mathrm{R}}{\mathrm{R}_{\mathrm{o}}}$

In Eq. $1 R$ is the actual rate of spread of the fire front. It is obvious that $R^{\prime}=1$ corresponds to the case of the absence of a slope or wind effects, but its value will be different from unity in all other cases. In the presence 
of an opposite wind flow or slope (fire spreading down a slope) the corresponding value of $R$ ' is also close to unity. The same happens for flank fires that spread perpendicular to the wind direction or a slope gradient. In the case of concurrent wind flow or upward slope the value of $R^{\prime}$ can vary in a range of two or three orders of magnitude. Although in general its value varies with time, it is common to estimate an average value of $R$ ' in order to predict fire spread.

\section{Non-existence of Steady-State Propagation}

One of the assumptions made in many fire spread models is that if the three sets of factors that were mentioned in the previous section, namely that if the fuel bed properties, the wind velocity and the terrain slope are specified, the rate of spread of the fire front can be definitively determined. This assumption is equivalent to stating that there is a unique solution to the problem of determining the rate of spread if the above mentioned parameters are defined.

Tests carried out by the present author and his team showed that, in general, even in the carefully controlled laboratory experiments the rate of spread changes with time [10]. This is, for example, the case of a fire front spreading on a slope, in a canyon or on flat ground with a constant wind velocity in which the rate of spread increases over time, meaning that for the same boundary conditions the fire can spread at different. This dynamic behaviour is caused by the convection produced by the fire even if the overall boundary conditions remain constant and uniform, means that time - the duration of the fire since its ignition — cannot be excluded from the problem of predicting fire behaviour in the general case.

\section{Fire-Line Rotation}

Another very common modeling assumption is that the rate of spread of the fire at a given point on its perimeter depends only on its local conditions (fuel properties, terrain slope and wind velocity) and that it is not affected by the fire conditions in the vicinity of that point [11]. We observed that convection around the fire front can modify the conditions of propagation of the fire even when the overall conditions are nominally the same along the entire fire front $[12,13]$. An example of this is the case of a linear fire front on a slope. If the fire-line is not horizontal and makes an angle $\beta \neq 0$ with the horizontal direction, the convective flow induced by the fire front that is mainly parallel to the slope gradient vector can be decomposed into a component perpendicular to the fire front and another that is parallel to it. This parallel or transverse component transports heat from the given point $P$ across the fire front and will contribute to enhancing the combustion at a nearby point $Q$ located above the point below. As a consequence of this additional energy the combustion will be enhanced at this second point $Q$ and the rate of spread will be slightly increased. It must be noted that in this case classical modeling would consider a uniform value for the rate of spread at all points of the fire-line, as the boundary conditions (fuel, wind and topography) are nominally the same along the entire line.

A consequence of the non-uniformity of the rate of spread along the fire line is that its movement cannot be described by a single value for the rate of spread as it is composed of a translational and a rotational component. A semi-empirical model to predict the local velocity of rotation of a fire-line element, based on the terrain geometry and fuel properties was proposed in Viegas and Rossa [14]. The application of this model can be made to predict the evolution of a point ignition fire on a slope and it explains the changes in the shape of the fire perimeter from an initial circular shape to a teardrop-like shape.

In the literature following Anderson et al. [15], it is commonly assumed that the spread of a fire in an arbitrary slope and wind condition is well represented by an elliptical form. Although this assumption can be adopted as a reasonable representation of the fire perimeter in many cases, a more rigorous analysis shows that in the general case of slope and wind driven fires, the shape of the fire is not symmetric and evolves in the course of time due to the existence of different convection processes along its perimeter [16].

\section{Extreme Fire Behaviour}

A very important local property of fire spread is the power that it releases per unit of fire-line length or fireline intensity $I\left(\mathrm{~J} \cdot \mathrm{s}^{-1} \cdot \mathrm{m}^{-1}\right)$, which is defined, following Byram [17] by:

$I=m_{c} \cdot H_{c} \cdot R$ 
In this equation $m_{c}$ is the fuel load $\left(\mathrm{kg} / \mathrm{m}^{2}\right)$ that is consumed by the spreading fire, $H_{c}$ is the heat released per unit mass of fuel $(\mathrm{J} / \mathrm{kg})$ and $R$ is the rate of spread of the fire $(\mathrm{m} / \mathrm{s})$. This parameter that is designated as fireline intensity is very much dependent on the value of the rate of spread that can change by several orders of magnitude. For a given fuel its value can be correlated empirically to the height of the flames [18].

The value of the fire-line intensity is also related to the capacity to suppress a spreading fire. Present day technology is not efficient to suppress a fire if its intensity is greater than $4000 \mathrm{~kW} / \mathrm{m}$ [19] which corresponds to a great challenge both to fire practitioners and researchers. This range of very high values of fire-line intensity is associated with an extreme fire behavior which may occur under extreme weather conditionshigh values of air temperature and wind velocity and low precipitation and relative humidity-or in the presence of steep slopes or canyons. Some examples of extreme fire behavior are described below.

\section{Eruptive Fires}

Viegas and Pita [20] observed that a fire in a canyon generally develops a head fire with an increasing rate of spread. This type of fire is designated as an eruptive fire given the sudden acceleration of its rate of spread. In a recent review by Viegas and Simeoni [21] the various processes or mechanisms that have been proposed in previous research to explain the sudden acceleration that characterizes these fires, were exposed and discussed: (i) feedback by the fire to the surrounding flow that is explained with more detail below; (ii) change of fuel bed properties, namely its moisture content, due to an eventual thermal belt that would cause a reduction of the fuel moisture content and a fire acceleration; (iii) change of wind conditions, namely its direction or velocity; (iv) presence of instability in the atmosphere, to justify the quick development of the fire; (v) accumulation of combustible gases ahead of the fire front that would burn suddenly in the form of an open-air flash-over; and (vi) flow attachment due to the accumulation of fire-line intensity in a transitory fire. The likely role of each one of the proposed mechanisms on the inception and development of an eruptive fire was analyzed and it was concluded that while the first mechanism is sufficient to explain a large number of cases that are recorded in the literature, some of the other processes may have some role in certain conditions or phases of the process. In the following the feedback mechanism shall be described to give its generality and robustness.

Based on laboratory tests and on field observations a mathematical model was developed by the present author $[22,23]$ to predict the variation of the rate of spread as a function of time for various types of fuel beds. This model is based on the feedback between the fire and the surrounding flow that induces an increase of the flow velocity and consequently of the rate of spread of the head fire. The change in the rate of spread with time is described by the following equation:

$$
\frac{d R^{\prime}}{d t}=a_{1}{ }^{1 / b_{1}} \cdot b_{1} \cdot a_{2} \cdot\left(R^{\prime}-1\right)^{\left(1-1 / b_{1}\right)} \cdot R^{1 b_{2}}
$$

where the parameters $a_{1}\left[(\mathrm{~m} / \mathrm{s})^{-b_{1}}\right], a_{2}\left(\mathrm{~m}^{\left(1-b_{2}\right)} / \mathrm{s}^{\left(2-b_{2}\right)}\right), b_{1}[-]$ and $b_{2}[-]$ are empirical coefficients that depend on the fuel properties and can be determined in laboratory or field experiments. If the model parameters are known and the initial conditions, in this case the initial rate of spread, are specified, this equation can be integrated and the variation in the rate of spread with time can be determined. Typical results produced by this model for three different fuels (herbaceous, HB; litter, LT and shrubs, SR) are shown in Fig. 1.

The very high values of the rate of spread that can be reached in these fires make them unstoppable, allowing them to be included in the type of extreme fires given the very high fire-line intensities that they can reach. Many accidents with multiple fatalities described in the literature $[22,24]$ are associated with this type of fire behavior.

The fact that eruptive fires can be created in laboratory-scale test rigs in controlled conditions and in the absence of the various mechanisms that were mentioned above supports the interpretation given for the generation of eruptive fires that is associated with the feedback between the fire and the surrounding flow. 


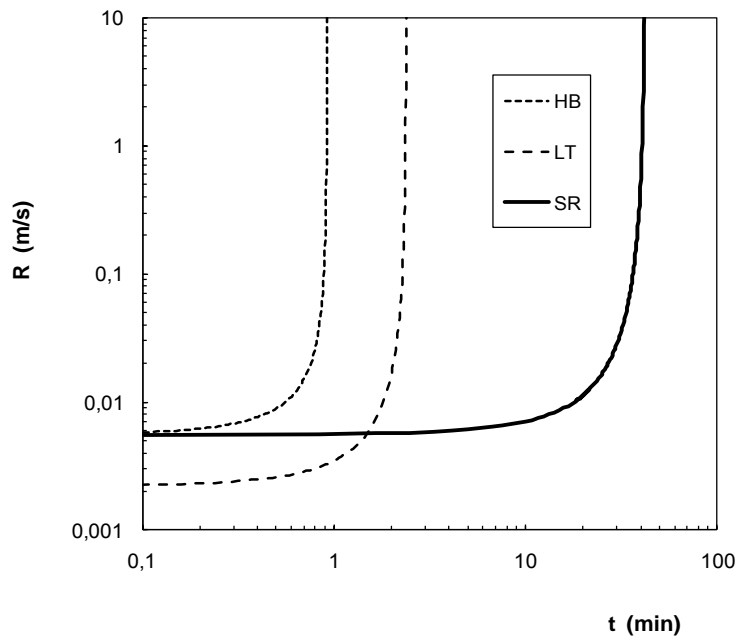

Fig. 1. Variation in the rate of spread with time for three typical forest fuels according to the eruptive fire behaviour model (Eq. 3). The meaning of the fuel designations is: HB - herbaceous; LT - forest litter and SR - shrubs.

\section{Jump Fires}

When two fire fronts approach each other, the convection produced by them induces an interaction between both fires. A case of particular interest that is being studied by the present author and his group is the one that is produced when two fire fronts merge forming a small angle between them. This situation is shown schematically in Fig. 2 in which two linear fire fronts $L_{1}$ and $L_{2}$ form an angle $\theta_{0}$. We assume that the two lines are similar and therefore the axis $O Y$ of Fig. 2 can be considered as a line of symmetry of the fire.

Laboratory experiments have shown that the merging of these two fire lines is accomplished by an advance of the intersection point $D$ between both lines along the $O Y$ axis with comparatively less movement of the fire lines. As a consequence the angle between the two fire lines increases, tending to become equal to $180^{\circ}$ which corresponds to a straight line. It was observed that for relatively small values of $\theta_{\mathrm{o}}$ the instantaneous velocity $V_{D}(\mathrm{~m} / \mathrm{s})$ of point $D$ increases very rapidly from practically zero to a very high value, and then decreases also relatively rapidly. We designate this type of fire as a jump fire, given the sudden increase that is observed in the value of $V_{D}$ that corresponds to a jump of this point and a very rapid advance of the fire along the $O Y$ axis (see Fig. 2), and consequently to very strong convection effects. A simple analytical model based on the accumulation of energy near $D$ was proposed by Viegas et al. [25] to explain the very high values of $V_{D}$ for small values of $\theta_{\mathrm{o}}$ and its rapid decrease with $\theta_{\mathrm{o}}$. Results from experiments performed on a horizontal fuel bed without wind, and with different initial values of $\theta_{0}$ are shown in Fig. 3, in comparison with the proposed analytical model. In this figure the displacement velocity is normalized using the same definition that was given in Eq. 1: $V^{\prime}{ }_{D}=V_{D} / R_{o}$. It must be noted that the measured values of $V_{D}$ were 60 times larger than the basic rate of the spread $R_{o}$, which is not usual to find in fires spreading on a horizontal surface even with a relatively strong wind. 


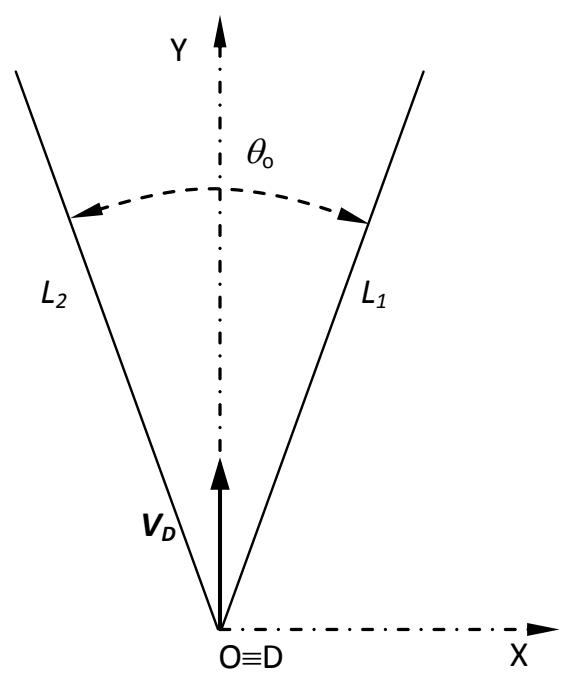

Fig. 2. Schematic view of the merging of two linear fire fronts making an initial angle $\theta_{\mathrm{o}}$ between them.

Experiments performed with an inclined fuel bed with a slope of $30^{\circ}$ produced values of $V_{D} 200$ to 300 times the value of $R_{o}$, indicating that a similar effect may occur in fires spreading with strong wind. This effect may justify the extreme fire behaviour that was observed in some fires, namely in those that spread towards Canberra in the early afternoon of 18 January of 2003.

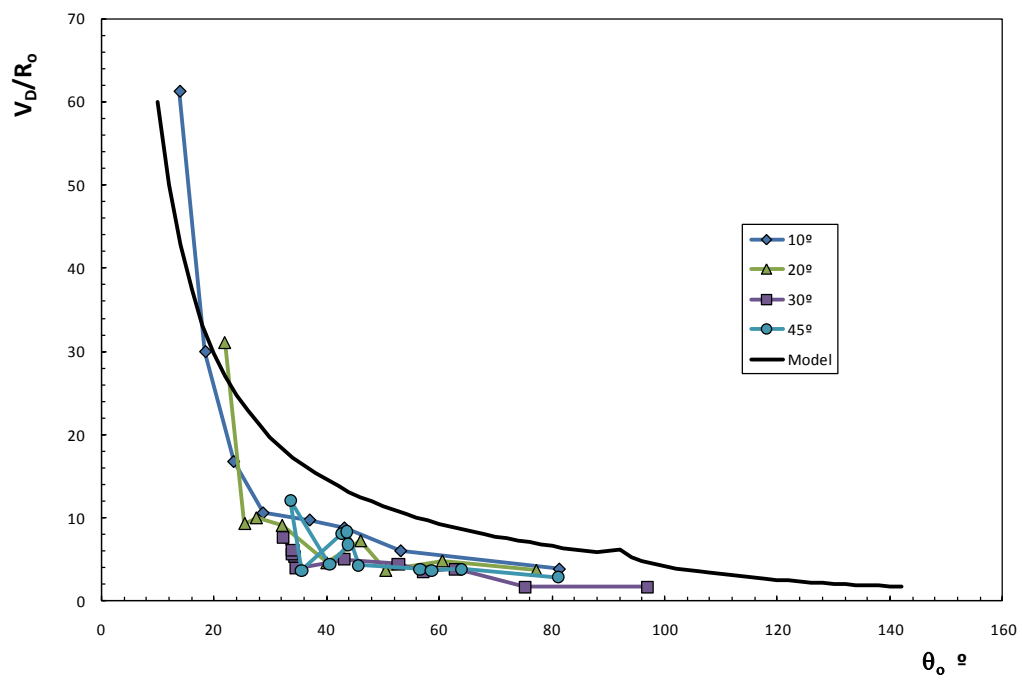

Fig. 3. Results obtained in laboratory experiments of the velocity of displacement $V_{D}$ as a function of the angle between the two fire lines in a series of tests on a horizontal fuel bed. The angles given in the legend correspond to the initial value of $\theta_{o}$ in each test.

\section{Spot Fires}

Burning embers transported by the fire plume and by wind may produce spot fires at small to large distances from the main fire front. The prediction of spot fires is very important in the simulation of forest fire propagation as they can greatly modify the behaviour of the fire, creating problems for fire suppression tactics and to the safety of firefighting personnel. It was observed that many accidents that are described in the literature [26-28] were triggered by spot fires and it is also recognized by Cohen [29] that one of the main mechanisms of house destruction by a fire in the wild-land urban interface is spotting.

Modeling spot fires is a very complex task given the large number of processes and factors that are involved in their development. We can summarize these processes as the following: (i) generation of embers by the fire, 
(ii) transport of the burning particles by the fire plume and by the ambient wind, (iii) combustion of the particles during their travel, and (iv) landing of the particles on a fuel bed and its ignition. As can be judged from this simplified description of the multiple processes involved in the occurrence of spot fires, they depend on a large number of factors that are not generally well. Therefore many known spot fire prediction models, like the one developed by Albini [30-32] and more recently by Sardoy [33], are essentially probabilistic as they attempt to predict the probability of having one or more spot fires and to estimate their average or maximum distance of occurrence.

The present author and his research group recently initiated an investigation of the mechanisms described above, applied to the case of some potential embers that are common in Portuguese forests, namely eucalyptus bark pieces. This research involves the study of the generation of embers by a burning tree in the laboratory using particle imagery velocimetry to determine the number, size, shape and velocity of the particles emitted during the burning of the tree. Almeida et al. [34] measured the aerodynamic coefficients of pieces of bark using a six component balance in an original oblique wind tunnel in which the particle was fixed and the incidence angle of the flow was changed by inclining the flow duct of the tunnel.

The burning of the particles in a surrounding flow was studied both in the oblique wind tunnel and in a vertical wind tunnel. The mass loss of the particle is well represented by the following equation:

$$
m=m_{o} \cdot e^{-k_{o} \cdot t}
$$

In this equation $m(\mathrm{~kg})$ is the instantaneous value of the particle that had an initial mass equal to $m_{o}(\mathrm{~kg})$, and $k_{o}\left(\mathrm{~s}^{-1}\right)$ is an exponential decay coefficient. Values of $k_{o}$ for eucalyptus bark with the shape of a circular cylinder-due to the curling tendency of the bark of this type of trees-with a length of $30 \mathrm{~cm}$ and an approximate diameter of $2 \mathrm{~cm}$ were measured for a range of conditions of flow velocity $U(\mathrm{~m} / \mathrm{s})$ and particle inclination $\theta$ in relation to the horizontal direction or its angle $\alpha$ in relation to the incident flow. Some tests were performed maintaining $U, \theta$ and $\alpha$ constant and in other tests one or more of these parameters was changed. These dynamic conditions should correspond to more realistic conditions of a burning particle immersed in a changing flow and assuming various angles of incidence in relation to the flow during its travel. Almeida et al. [35] found that the values of $k_{o}$ determined in the dynamic tests were far superior to those measured in the static conditions, indicating that a significant error can be committed in the evaluation of travel or combustion duration of the particle if these changes are not taken into account.

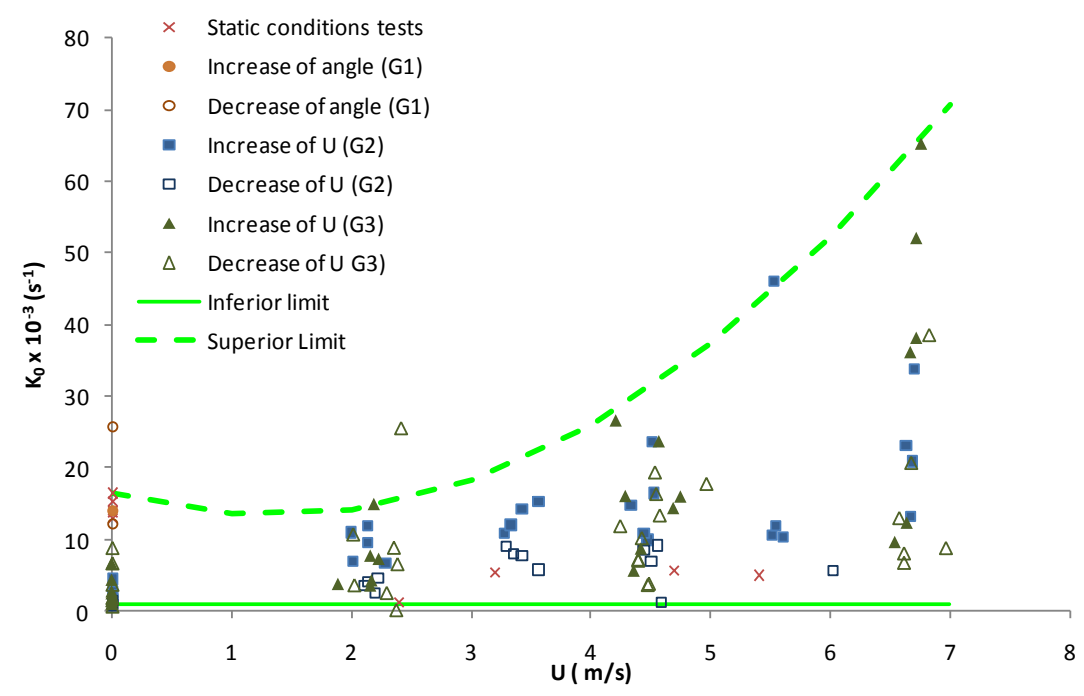

Fig. 4. Variation of coefficient $k_{o}$ for eucalyptus bark as a function of flow velocity in the case of varying test conditions. The static tests correspond to constant values of both $\theta$ and $U$. In the group of tests with reference

G1 the angle $\theta$ of the particle was changed in steps of $45^{\circ}$; for group G2 the flow velocity was varied gradually; for group G3 the velocity was changed in larger steps than in the previous case. 
The transport of burning particles in the atmospheric flow is being modeled numerically by Oliveira et al. [36] by taking into account the exchange of mass, momentum and energy between the particle and the flow. The probability of ignition of burning pieces of bark landing on a fuel bed composed of typical species that can be found in Portuguese forests was studied in the laboratory by Pita et al. [37]. The results of a relatively large number of tests are shown in Fig. 5 in the form of the average probability of ignition as a function of the moisture content $m_{f}$ of the fuel bed. As can be seen in this figure for low values of $m_{f}$ the probability of ignition is quite high while for values of $m_{f}>20 \%$ this probability decays practically linearly until becoming almost zero for $m_{f}>120 \%$. Our results show that there was no great difference between the three fuel beds tested. It must be noted that these experiments were made without wind and in these conditions positive ignition was only obtained with particles burning with a flame before being dropped on the fuel bed.

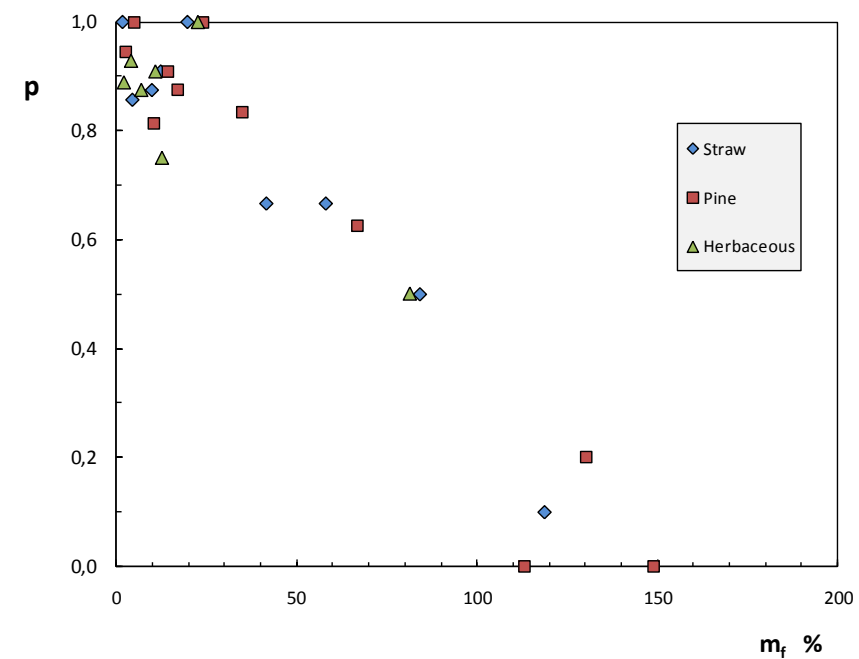

Fig. 5. Probability of ignition of a fuel bed by a flaming particle of eucalyptus bark falling freely on three types of fuels as a function of their average moisture content.

\section{FIRE BEHAVIOUR AND FIRE SAFETY}

\section{Some Case Studies}

The present author studied several cases of fire-related accidents in which one or more lives were lost. As was mentioned earlier many of these cases were associated with eruptive fire behavior, reinforcing our conviction that it is important to take into account the dynamic behaviour of the fire to improve personal safety in forest fires. In Viegas [24] some recent accidents associated with eruptive fires that occurred in Europe are described. Two of these cases are summarized here as an illustration of the concepts that were exposed.

\section{Guadalajara Incident}

This incident occurred in the province of Guadalajara, in Central Spain on the 17 July 2005. In it 11 firefighters of a group of 12 lost their lives, who were attempting to attack the flank of a very large fire that started the day before. The group was working on a ridge above a very large double canyon for about twenty minutes when they were surprised by a violent eruption in one of the slopes of the canyon below them, Fig. 6 . Most probably this eruption was caused by an ember produced by the flank fire that fell in the bottom of the valley unseen by the group, which burned the pine stand that can be seen in Fig. 6 on the right hand side slope. The leader of the group ordered an immediate escape in the four vehicles that they were using from the pine stand that can be seen on the line of horizon on the centre right side of the picture. When the vehicles attempted to go back along the same route that they had used in their approach to the fire, a second eruption occurred on the other side of the canyon about five minutes later, leaving no chance for the group to escape. There was only one survivor who was the driver of the fourth vehicle, who departed late and having lost visibility due to the smoke lingering in the same place where the group had been fighting the fire. He took refuge below a fire truck and remained in an area with practically no vegetation that could be seen near the ridge. Although he suffered burns, he survived. More details can be found in Ref. [28]. 


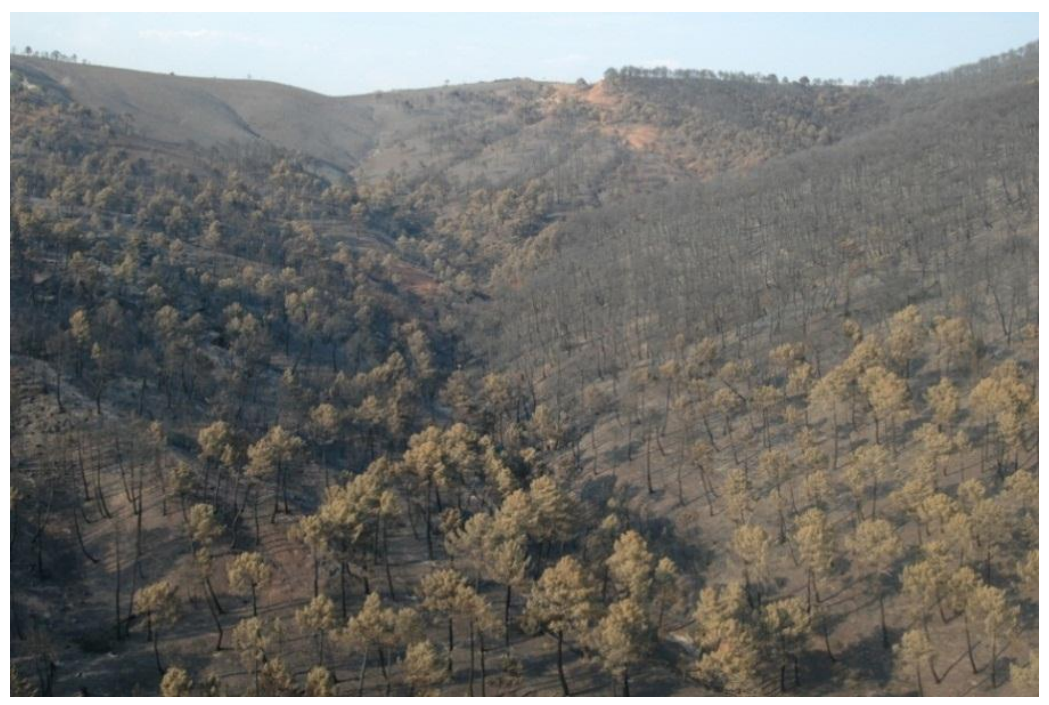

Fig. 6. General view of the double canyon below the site where the accident of Guadalajara occurred.

\section{Famalicão Incident}

This incident resulted in six victims in a fire that had started two hours before on the 9 July 2006 near Famalicão da Serra in Central Portugal, as described in more detail in Ref. [38]. This fire was also caused by accident and spread quite rapidly on a slope into a pine stand, Fig. 7. The group of six firefighters-five of Chilean nationality and one Portuguese-was attacking the flank fire spreading in the litter layer of the pine stand against the wind, near the edge of the unburned pine canopies that can be seen on the right hand slope in Fig. 7. Suddenly the fire crowned in front of them, as shown by the dark strips on the triangular-shaped pine stand, and the group decided to escape along the slope in the opposite direction of the fire. Doing so they went towards the centre of the large canyon formed by two slopes one of which was the one where they were fighting the fire. In the meantime, and unknown to them, the fire spreading at the bottom of the valley reached the water line of the canyon and entered the left side slope. The fire spread with great violence on both slopes so the group of firefighters was caught in the middle of two very intense fire fronts that left them no escape.

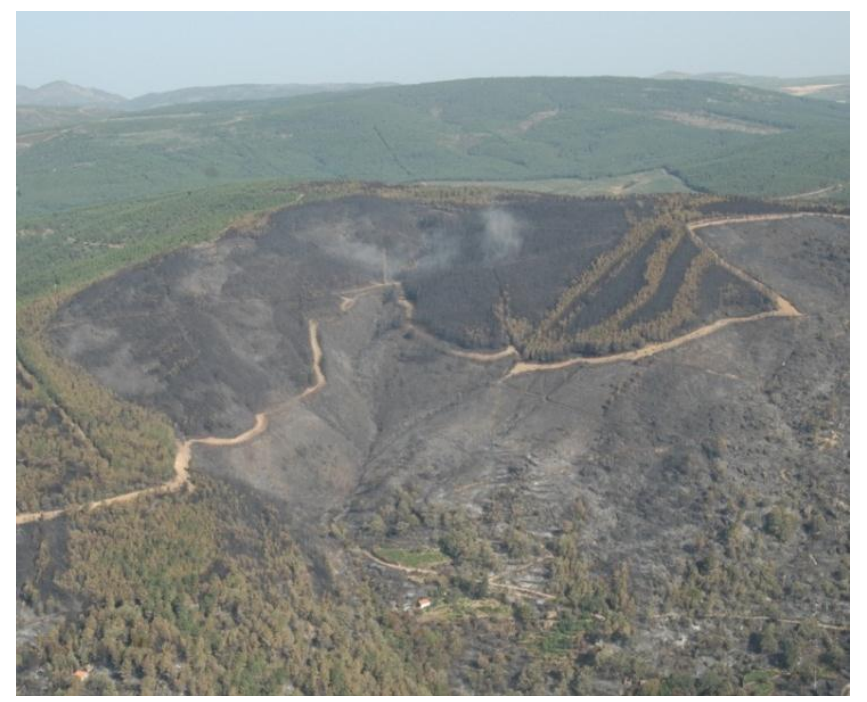

Fig. 7. General view of the canyon where the Famalicão incident occurred.

Victoria 2009 Fires

On the 7 February 2009 after a prolonged drought and with extreme meteorological conditions - air temperature above $42{ }^{\circ} \mathrm{C}$, relative humidity below $5 \%$ and wind velocity of the order of 80 to $90 \mathrm{~km} / \mathrm{h}$ - fires 
that spread in the state of Victoria in Southern Australia devastated more than 400 thousand hectares and killed 173 persons in about six hours. For more details see Ref. [19]. This is probably the worst disaster associated with forest fires recorded in recent history especially due to the tremendous loss of lives. On this day more than 200 fires started or were already spreading under the very severe conditions that were just described. Most of the fires were suppressed at an early stage, but eight of them that were not controlled caused the destruction of several villages in the middle of the eucalyptus forest, Fig. 8. Pushed by strong winds from the northwest, the fires propagated very rapidly with many spot fires falling two to seven kilometers ahead of the main fire front. One of the factors that contributed to the large loss of life was the fact that in the mid-afternoon a change of wind direction from northwest to southwest caused the very long left flanks of most fires to become huge fronts, that surprised not only the firefighting forces but also the population that could not react in time and was effectively caught in the face of such an extreme spreading fire. It was found that current fire prediction models that were used by operational authorities constantly under-predicted the rate of advance of the fire. The analysis of fire spread also exposed the insufficient knowledge of the mechanisms of spot fires that were very relevant during these fires.

This disaster should be considered as an indication of what can happen in any part of the world under extreme weather conditions. It motivated among the Australian operational and scientific communities a thorough investigation of the circumstances in which it developed with the purpose of learning lessons to avoid or minimize such problems in the future. It is worth noting that one of the adopted measures was the consideration that the previously existing fire danger rating system was not adequate to discriminate these extreme fire conditions. A sixth level designated 'catastrophic fire' was added to the existing five level fire danger scale and is now in use in Australia.

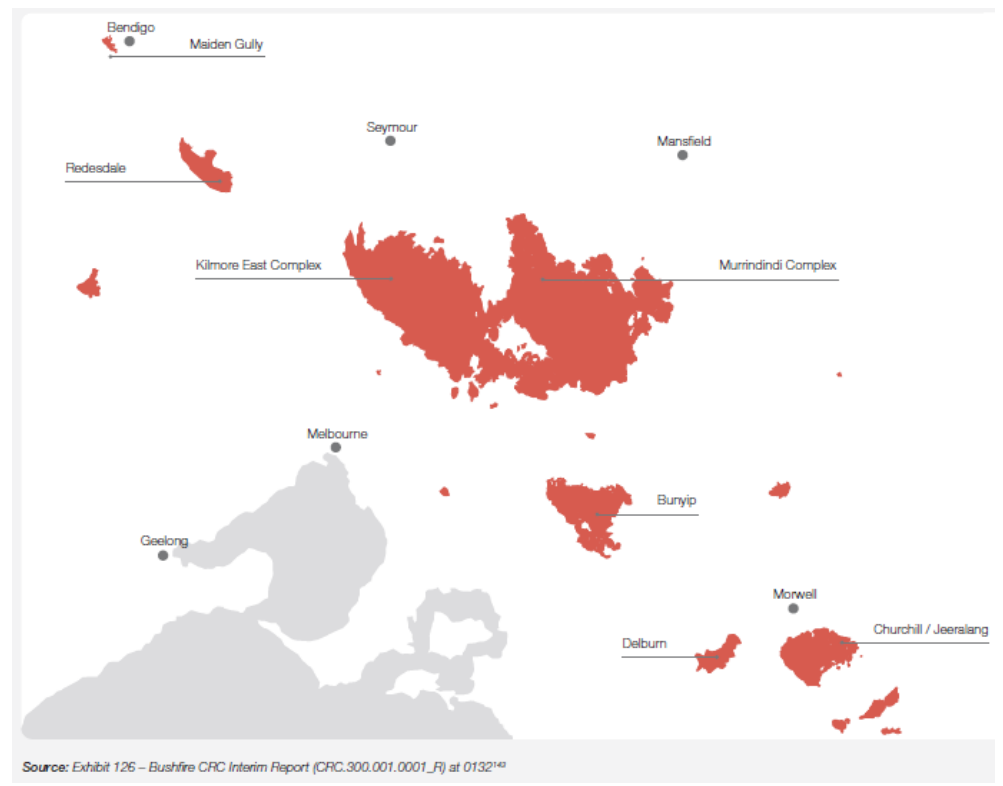

Fig. 8. Final perimeters of some of the main fires that occurred in the state of Victoria on the 7 February 2009 in the vicinity of Melbourne.

\section{CONCLUSION}

An overview of the problem of forest fire propagation modeling was provided with emphasis on fire safety related issues. The main problems associated with fire behaviour modeling were mentioned and some research topics that are being developed by this author and his co-workers were described. The need to consider explicitly the time dependence in the evaluation of the rate of spread of a fire front in arbitrary conditions was shown. This dependence is particularly important in the case of eruptive fires that spread on steep slopes or in canyons, producing a rapid acceleration of the fire front in a relatively short time. This behaviour is interpreted by the present author as the result of the feedback mechanism between the fire and its surrounding flow.

The concept of jump fires was introduced to describe the behaviour of two linear fire fronts that merge forming a small angle between them. It was shown that in symmetrical conditions the intersection point of the 
velocity of displacement of the intersection point decreases in the course of time while the angle between the two fire lines increases, tending to a value of $180^{\circ}$ that corresponds to a straight line.

The difficulties associated with the modeling of spot fires were mentioned and some results of an ongoing research into this problem were presented.

Some case studies of fires that spread in canyons or under extreme weather conditions were described briefly in order to illustrate the relevance of the problem of fire behaviour modeling and some of its implications in the protection of life and property.

\section{ACKNOWLEDGMENTS}

The author wishes to thank the organizers for the invitation to present this lecture in forest fire propagation at this prestigious conference.

The support given by the members of his team, namely to A. Figueiredo, C. Rossa, L. Ribeiro, T. Viegas, L. Pita, M. Almeida, L. Oliveira, D. Davim, J. Raposo and C. Viegas, in the scope of the research activity presented in this paper is gratefully acknowledged.

The author also wishes to thank provided by the Fundação para a Ciência e Tecnologia for the financial support given to the present research program trough Project SPOTFIRE (Contract ptdc/ememfe/73765/2006).

\section{REFERENCES}

[1] Carvalho, A., "Alterações climáticas e risco meteorológico de incêndio florestal", Departamento de Ambiente e Ordenamento, Universidade de Aveiro, Aveiro, Mestrado, 2002, (In Portuguese), 116 pp.

[2] Sullivan, A.L., (2009) Wildland surface fire spread modeling, 1990-2007. 1: Physical and quasiphysical models, International Journal of Wildland Fire 18: 349-368. http://dx.doi.org/10.1071/WF06143

[3] Sullivan, A.L., (2009) Wildland surface fire spread modeling, 1990-2007. 2: Empirical and quasiempirical models, International Journal of Wildland Fire 18: 369-386. http://dx.doi.org/10.1071/WF06142

[4] Sullivan, A.L., (2009) Wildland surface fire spread modeling, 1990-2007. 3: Simulation and mathematical analogue models, International Journal of Wildland Fire 18: 387-403, http://dx.doi.org/10.1071/WF06144

[5] Linn, R.R., "A transport model for prediction of wildfire behavior", PhD thesis, New Mexico State University, also published as Los Alamos Report, LA-13334-T, 1997.

[6] Morvan, D. and Larini, M., (2001) Modeling of one-dimensional fire spread in pine needles with opposing air flow, Combustion Science and technology 164: 37-64, http://dx.doi.org/10.1080/00102200108952161

[7] Séro-Guillaume, O. and Margerit, J, (2002) Modeling forest fires. Part I: A complete set of equations derived by extended irreversible thermodynamics, International Journal of Heat and Mass Transfer 45: 1705-1722, http://dx.doi.org/10.1016/S0017-9310(01)00248-4

[8] Albini, F.A., (1985) A model for fire spread in wildland fuels by radiation, Combustion Science and Technology 42: 229-258, http://dx.doi.org/10.1080/00102208508960381

[9] Rothermel, R.C. "A mathematical model for predicting fire spread in wildland fuels", USDA Forest Service Research Paper INT-115, 1972, 40 p.

[10] Viegas, D.X., (2004) On the existence of a steady-state regime for slope and wind driven fire, International Journal of Wildland Fire 13: 101-117, http://dx.doi.org/10.1071/WF03008

[11] Rothermel, R.C., "How to predict the spread and intensity of forest and range fires", USDA Forest Service, General Technical Report, INT-143, 1983, 161p.

[12] Viegas, D.X., (1998) Forest fire propagation, Philosophical Transactions of the Royal Society A, 356: 2907-2928, http://dx.doi.org/10.1098/rsta.1998.0303 
[13] Viegas, D.X., (2002) Fire line rotation as a mechanism for fire spread on a uniform slope, International Journal of Wildland Fire, 11: 11-23, http://dx.doi.org/10.1071/WF01049

[14] Viegas, D.X. and Rossa C., (2009) Fireline Rotation Analysis, Combustion Science and Technology, 181: 1495-1525, http://dx.doi.org/10.1080/00102200903228891

[15] Anderson, D.H., Catchpole, E.A., De Mestre, N.J., and Parkes, T. 1982. Modelling the spread of grass fires. Journal of Australian Mathematical Society (Series B), 23, 451-466.

[16] Viegas, D.X., (2004) Slope and wind effects on fire propagation, International Journal of Wildland Fire, 13: 143 - 156, http://dx.doi.org/10.1071/WF03046

[17] Byram, G.M. "Combustion of forest fuels" In: Davis, K.P., ed. Forest fire: control and use. New York: McGraw Hill, 1959, p. 61/89.

[18] Chandler, C., Cheney, P., Thomas, P., Trabaud, L., and Williams, D. Fire in Forestry, Vol.I, John Wiley and Sons, 1983.

[19] Victorian Bushfires Royal Commission, 2009. Interim Report, 17 August 2009.

[20] Viegas, D.X. and Pita, L.P., (2004) Fire Spread in Canyons, International Journal of Wildland Fire. 13:1-22, 274, http://dx.doi.org/10.1071/WF03050

[21] Viegas, D.X. and Simeoni, A., (2010) Eruptive Behaviour of Forest Fires, Fire Technology, Invited review, published on-line 22 October 2010. http://dx.doi.org/10.1007/s10694-010-0193-6

[22] Viegas, D.X., (2005) A Mathematical Model for Forest Fires Blow-up, Combustion Science and Technology 177: 27-51, http://dx.doi.org/10.1080/00102200590883624

[23] Viegas, D.X., (2006) Parametric Study of an Eruptive Fire Behaviour Model, International Journal of Wildland Fire. 15:169-177, http://dx.doi.org/10.1071/WF05050

[24] Viegas, D.X. (Ed.), Recent Forest Fire Related Accidents in Europe. JRC Scientific and Technical Reports, Joint Research Centre, Institute for Environment and Sustainability, European Commission, 2009, JRC 56107, EUR 24121 EN, ISBN 978-92-79-14604-6, 75p.

[25] Viegas D.X., Davim, D., Rossa, C. and Raposo, J., (2010) Study of the Jump Fire Produced by the Interaction of Two Oblique Fire Fronts. Part 1: Analytical Model and Validation with No-slope Laboratory Experiments, International Journal of Wildland Fire (Submitted)

[26] Rothermel, R.C. “Mann Gulch Fire: A Race That Couldn't Be Won”, USDA Intermountain Research Station, Gen. Tech. Rep. INT-299, 1993.

[27] Butler, B.W., Bartlette, R.A., Bradshaw, L.S., Cohen, J.D., Andrews, P.L., Putnam, T., and Mangan, R.J. "Fire behaviour associated with the 1994 South Canyon fire on Storm King Mountain, Colorado", Res. Pap. RMRS-RP-9. Ogden, UT: U.S. Department of Agriculture, Forest Service, Rocky Mountain Research Station, 1998, 82 p.

[28] Viegas, D.X., Caballero, D., "The accident of Guadalajara (Spain)", Viegas DX (ed) Recent forest fire accidents in Europe. JRC-IES, European Commission, Ispra, Italy, 2009, ISBN 978-92-7914604-6.

[29] Cohen, J., (2008) The Wildland Urban Interface Fire Problem, Forest History Today, Fall 2008, 2026.

[30] Albini, F., (1983) Transport of firebrands by line thermals, Combustion and Flame 32: 277-288, http://dx.doi.org/10.1080/00102208308923662

[31] Albini, F., "Spot Fire Distances From Burning Trees - A Predictive Model”, USDA Forest Service, General Technical Report INT-56, Missoula, MT, 1979.

[32] Albini, F., "Potential Spotting Distance from Wind-Driven Surface Fires", USDA Forest Service, Research paper INT-309, Missoula, MT, 1983, 27 p.

[33] Sardoy, N., Consalvi, J.L., Porterie, B. and Fernandez-Pello A.C., (2007) Modeling transport and combustion of firebrands from burning trees, Combustion and Flame 150: 151-169. 
[34] Almeida, M., Viegas, D.X., Miranda, A.I., Viegas C. and Leitão N., "Aerodynamic Characteristics of Some Potential Embers". Proceedings of the $6^{\text {th }}$ International Conference on Forest Fire Research. 15-18 ${ }^{\text {th }}$ November 2010, Coimbra. Ediliber, Lda. ISBN: 978-989-20-2157-7.

[35] Almeida, M., Viegas, D.X., Reva, V., Miranda, A.I. and Leitão, N., "Burning of Embers with Flow Incidence and Spin". Proceedings of the $6^{\text {th }}$ International Conference on Forest Fire Research. $15-18^{\text {th }}$ November 2010, Coimbra. Ediliber, Lda. ISBN: 978-989-20-2157-7.

[36] Oliveira, L.A., Lopes, A.M.G., Baliga, B.R., Viegas, C.X. and Viegas, D.X., "Numerical predictions of properties and trajectories of wind driven firebrands". Proceedings of the $6^{\text {th }}$ International Conference on Forest Fire Research. 15-18 ${ }^{\text {th }}$ November 2010, Coimbra. Ediliber, Lda. ISBN: 978989-20-2157-7.

[37] Pita, L.P., Viegas, D.X., Gaspar, S. and Schumann, J., "Fuel Beds Ignition by Eucalyptus Bark" Proceedings of the $6^{\text {th }}$ International Conference on Forest Fire Research. 15-18 ${ }^{\text {th }}$ November 2010, Coimbra. Ediliber, Lda. ISBN: 978-989-20-2157-7.

[38] Viegas, D.X., Pita, L.P., Ribeiro, L.M., "The accident of Famalicão (Portugal)" Viegas DX (ed) Recent forest fire accidents in Europe. JRC-IES, European Commission, Ispra, Italy, 2009, ISBN 978-92-79-14604-6. 